\title{
Addressing Opioid-Related Chemical Coping in Long-Term Opioid Therapy for Chronic Noncancer Pain: A Multicenter, Observational, Cross-Sectional Study
}

\author{
Anyela Marcela Castañeda ${ }^{1}$, Chang-Soon Lee ${ }^{1}$, Yong-Chul Kim ${ }^{1}$, Dasom Lee ${ }^{2}{ }^{\mathbb{D}}$ and \\ Jee Youn Moon $1,3, *$ (D) \\ 1 Department of Anesthesiology and Pain Medicine, Seoul National University Hospital College of Medicine, \\ 101Daehak-ro, Jongno-gu, Seoul 03080, Korea; anymarcey@hotmail.com (A.M.C.); \\ iparid@gmail.com (C.-S.L.); pain@snu.ac.kr (Y.-C.K.) \\ 2 Department of Psychiatry, Seoul National University Hospital College of Medicine, 101 Daehak-ro, \\ Jongno-gu, Seoul 03080, Korea; ds.elena.lee@gmail.com \\ 3 Department of Integrated Cancer Care Center, Seoul National University Cancer Hospital, 101 Daehak-ro, \\ Jongno-gu, Seoul 03080, Korea \\ * Correspondence: jymoon0901@gmail.com; Tel.: +82-2-2072-2462; Fax: +82-2-763-9390
}

Received: 1 September 2018; Accepted: 13 October 2018; Published: 14 October 2018

check for updates

\begin{abstract}
Opioid consumption has increased worldwide, which carries the risk of opioid use disorder (OUD). However, the literature on OUD and opioid-related chemical coping (OrCC) in chronic noncancer pain $(\mathrm{CNCP})$ is heterogeneous, with most studies conducted in the United States. We performed a multicenter, observational, cross-sectional study to address OrCC in long-term opioid therapy (LtOT) for CNCP in South Korea. The objectives were to determine the frequency and predictors of OrCC. We included 258 patients. Among them, fifty-five (21\%) patients showed OrCC. The sample had high pain catastrophizing ( $\geq 30$ points; 66\%), moderate-severe insomnia ( $\geq 15$ points; $63 \%$ ), low resilience (68 points), and high suicidal ideation (67\%). OrCC patients had greater pain interference $(85.18 \%$ vs. $58.28 \%, p=0.017)$ and lower satisfaction with the LtOT $(56.4 \%$ vs. $78.3 \%, p=0.002)$. In multivariable analysis, alcohol abuse (OR $=6.84, p=0.001)$, prescription drugs abuse $(\mathrm{OR}=19.32, p=0.016)$, functional pain $(\mathrm{OR}=12.96, p<0.001)$, head and neck pain $(\mathrm{OR}=2.48, p=0.039), \mathrm{MEDD}$ (morphine equivalent daily dose $) \geq 200 \mathrm{mg} /$ day $(\mathrm{OR}=3.48, p=0.006)$, and ongoing litigation ( $\mathrm{OR}=2.33, p=0.047$ ) were significant predictors of OrCC. In conclusion, the break-out of OrCC in CNCP in South Korea was comparable to those in countries with high opioid consumption, such as the United States, regardless of the country's opioid consumption rate.
\end{abstract}

Keywords: chronic noncancer pain; opioids; opioid use disorder; chemical coping; frequency; long-term opioids; risk factors

\section{Introduction}

Chronic pain is a devastating disease that is often treated inadequately [1]. Among a plethora of treatments, opioid agonists are one pharmacotherapy for moderate-severe pain. Although its consumption by country (mg/capita) has increased in the last two decades [2-4], it may remain under-requirements for managing moderate-severe pain in some regions, including Asian countries [1,4,5]. According to the 2015 opioid consumption data, the medical opioid consumption in the United States (U.S.) was $678 \mathrm{mg} /$ capita while in South Korea (S. Korea), it was $55 \mathrm{mg} / \mathrm{capita}$ which was below average, ranking 43rd globally and 30th among thirty-five Organisation for Economic 
Cooperation and Development (OECD) countries (258 mg/capita average in OECD countries) [4]. However, it is remarkable that the opioid consumption in S. Korea has increased 5-6 times since 2005 (10 mg/capita), ranking 3rd among Asian countries preceded only by Vietnam (62 mg/capita) and Malaysia (60 mg/capita).

Many clinicians are reluctant to prescribe opioids due to the risk of opioid use disorder (OUD) secondary to the induced reward responses to the drug [6]. In chronic noncancer pain (CNCP), concerns regarding drug dependence from long-term opioid therapy (LtOT), increased all-cause mortality, and poor long-term treatment results in terms of pain relief and quality of life have made the use of opioids controversial [7-10]. The spectrum of OUD in CNCP is wide and varies from opioid abuse to addiction [11]. Between these extremes, opioid-related chemical coping (OrCC) is the use of opioids to cope with emotional distress characterized by inappropriate and/or excessive opioid use [12]. OrCC should be distinguished from addiction, a brain disease that involves neuroplasticity and substantial loss of self-control [13]. All addicts are chemical copers, but not all chemical copers are addicts [11]. Although OrCC was first defined in cancer patients [14], the correlation with OUD in CNCP patients is high [15]. Therefore, understanding this intermediate status may prompt the identification of risk factors for severe OUD and prevention of unnecessary opioid toxicity [16].

The literature on OUD and OrCC is heterogeneous, and an overwhelming majority of the studies took place in the U.S. [7,17-19], a country with high opioid consumption rates [5] and a current opioid epidemic. In the U.S., drug overdose deaths (the majority involving an opioid) have nearly quadrupled since 1999 [2], and growing evidence suggests no benefits of the LtOT over non-opioid therapy in $\mathrm{CNCP}$ patients [9]. However, despite the high consumption rates of opioids, other studies suggest that CNCP remains undertreated $[1,20-23]$ and stringent regulations to prevent opioid abuse and addiction may result in inadequate pain control [24], especially in countries with low opioid consumption rates $[4,5]$. Moreover, it is uncertain if OUD is correlated with the country's overall consumption rates of opioids (mg/capita). Consequently, it may be necessary to determine the frequency and characteristics of OUD in CNCP patients in countries with low-moderate opioid consumption rates.

Given the above, we performed a national, multicenter, observational study to address OrCC, the intermediate status of OUD, in LtOT for CNCP in S. Korea, a country with moderate opioid consumption rates [5]. The objectives of this study were to estimate the frequency of OrCC, to evaluate the patient's functional and psychiatric characteristics, and to determine the risk factors associated with OrCC.

\section{Materials and Methods}

This national, observational, cross-sectional study was conducted in eight tertiary university-based hospitals in S. Korea between April 2017 and January 2018. The study was conducted in accordance with the Declaration of Helsinki, and the protocol was approved by the Institutional Review Boards (IRB) in each hospital. The protocol of the study was registered and openly shared in ClinicalTrials.gov (NCT03161795) to stress in the transparency of the research conduction. Eleven pain specialists, one neuropsychiatrist, and one oncologist took part in the study. Written informed consent was obtained from each participant prior enrollment. All methods and results have been reported according to the STROBE recommendations [25].

\subsection{Study Participants}

Inclusion criteria: (1) age $\geq 18$ years; (2) diagnosis of chronic pain defined by the International Association for the Study of Pain (IASP) as persistent or recurrent pain lasting longer than 3 months or past the time of normal tissue healing [26]; (3) patients with LtOT defined as the current and regular use of one or more opioid prescriptions for $\geq 3$ months; and (4) patients who completed the questionnaires administered in the study.

Exclusion criteria: (1) patients with a cancer diagnosis and/or receiving ongoing cancer treatment, palliative care, or end-of-life care; (2) patients who received opioid therapy for $<3$ months or 
intermittently; (3) patients with serious systemic diseases or acute psychiatric disorders that required inpatient management (schizophrenia, anxiety, depression, etc.), which compromised their safety or the completion of the study; or (4) patients with intellectual impairment and unable to answer the survey questions.

\subsection{Evaluation of Opioid-Related Chemical Coping}

The evaluation of OrCC was discussed by eleven anesthesiologists, one neuropsychiatrist, and one oncologist in the initial expert meeting. The presence of OrCC was determined through a questionnaire that contained seven behaviors related to OrCC. The questionnaire was based in a previous study of OrCC [12] and the DSM-5 diagnostic criteria of OUD [27] (Table 1). Two or more affirmative answers to the questionnaire were considered positive for OrCC. The questionnaire was reviewed through two additional educational meetings that were held prior to the patient's enrollment to reduce bias between physicians. A pain specialist at each participating hospital evaluated the presence of OrCC, thus the self-administered chemical coping inventory (CCI) was not considered for this study [11].

Table 1. Opioid-related chemical coping definition and questionnaire for physicians.

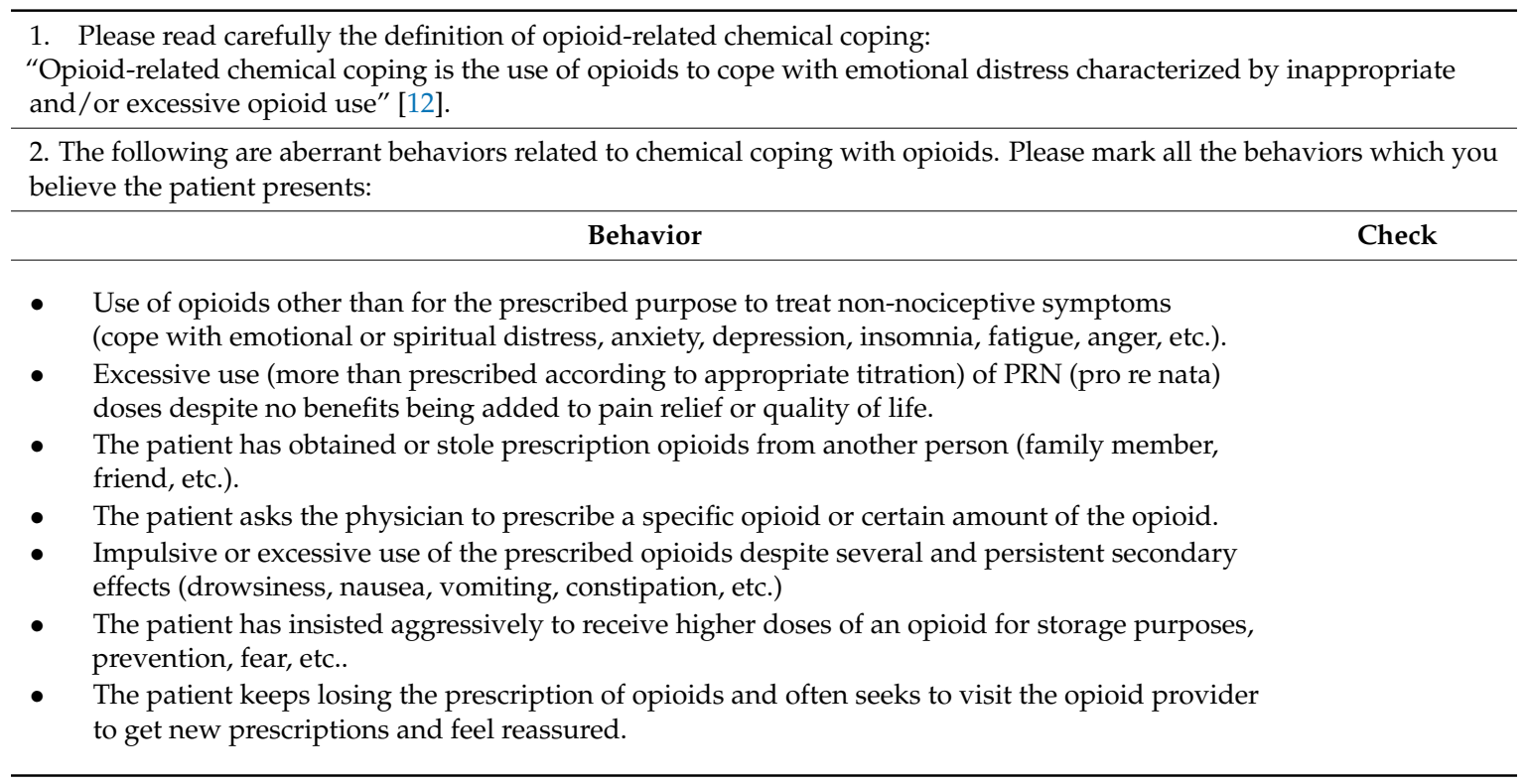

\subsection{Outcome Measurements}

Patients' sociodemographic data were obtained from the electronic medical record (EMR) including educational level ( $<$ high school or $\geq$ high school) and religion (yes $=$ Christianity, Islam, Buddhism, Hinduism, Taoism, etc.; no = Atheism), pain characteristics (including pain intensity using an 11-point numerical rating scale (NRS)) [28], co-morbid psychopathologies, substance abuse history within 1 year, and secondary morbid gain (if the patient's pain allows him/her to miss work, avoid military duty, obtain financial compensation, obtain drugs, etc.). We also collected opioid information, which included the duration of administration, opioid name and type, administration route, morphine equivalent daily dose (MEDD, mg/day) [29], initial prescribers, number of opioid-seeking medical/emergency room visits per year, and co-prescription of benzodiazepines or other medication. The information that was unavailable in the EMR was asked directly to the patient when appropriate. The tools and questionnaires administered in this study were divided into patient's and physician's booklets. The physician's booklet included a questionnaire to assess the patient's OrCC (Table 1) and the patient's booklet contained predictive tools for OUD and questionnaires to address functionality. 
The risks of LtOT were assessed through a survey in the outpatient setting of each pain clinic. After obtaining written, informed consent, the patients received a patient's booklet and responded to the following questionnaires and forms: (1) Cut down, Annoyed, Guilty, Eye-opener Adapted to Include Drugs (CAGE-AID) [30]; (2) Brief Pain Inventory-Short Form (BPI-SF) [31]; (3) Pain Catastrophizing Scale (PCS) [32]; (4) Hospital Anxiety and Depression Scale (HADS) [33]; (5) Insomnia Severity Index (ISI) [34]; (6) Korean Instrumental Activities of Daily Living Scale (K-IADL) [35]; (7) Korean Connor-Davidson Resilience Scale (K-CD-RISC) [36]; and (8) Patient Global Impression of Change Scale (PGIC) [37]. Among the four questions in the CAGE-AID, one or more affirmative answers was considered "positive" for OUD [38]. BPI-SF measured pain intensity (Items 3-6) and pain interference (Item 9) [39], which had seven components scored from 0 (no interference) to 10 (interferes completely). PCS had 13 items rated from 0 (not at all) to 4 (all the time); a total score $\geq 30$ was considered "catastrophizing" [32]. HADS scores for anxiety and depression ranged from 0 to 21 , with $\geq 11$ points considered "abnormal" [40]. The ISI total score ranged 0-28; scores ranging from 15-21 and 22-28 indicated moderate and severe insomnia, respectively [41]. K-IADL evaluated daily activities with 11 questions rated from 0 (independently performed/normal) to 3 (impossible to perform) [42]. $\mathrm{K}-\mathrm{CD}-\mathrm{RISC}$ had 25 items, rated from $0-4$, with higher scores reflecting greater resilience [43]. PGIC was rated from 1 (very much improved) to 7 (very much worse) [44]. Patients' overall satisfaction with their LtOT ranged from 1 (extremely satisfied) to 5 (extremely unsatisfied). A question to evaluate the presence of suicidal ideation in CNCP was also included (yes = previous suicidal attempts, thoughts of ending one's life, planned to commit suicide, wish to be dead; no = never attempted or thought about committing suicide). Additionally, adverse and undesirable effects of opioids were collected.

On the survey day, after answering the patient's booklet, each patient attended a routine visit with a pain specialist. Once the patient exited the room, the specialist answered the questionnaire to assess the patient's OrCC (Table 1) included in the physician's booklet.

\subsection{Sample Size Calculation and Statistical Analysis}

The precision/absolute error and the significance level were set at $5 \%$ and $95 \%$, respectively (Type 1 error of $5 \%, \alpha=0.05$ ). According to a published study by Kwon et al. [17], the prevalence of chemical coping was approximately $18 \%$; therefore, the sample size was calculated to be 235 participants. Considering a 10\% dropout rate, a group of 258 participants was planned for recruitment.

Depending on the data distribution, independent $t$-tests or Wilcoxon rank sum tests were performed to compare two independent groups. A paired $t$-test was used to compare two means from the same group. Categorical data were analyzed using Pearson's $\chi^{2}$ test, Fischer's exact test or Chi-square test. The normality distribution for continuous variables was assessed with the Kolmogorov-Smirnov test. The independent $t$-test was used to compare normal distribution and the Mann-Whitney U test was used for non-normal distribution.

Univariable analysis was performed to explore variables associated with OrCC, using the presence of $\mathrm{OrCC}$ as a dependent variable and clinical variables that included sociodemographic data, pain characteristics, opioid information, scores of CAGE-AID, K-IADL, PCS, and BPI-SF, as independent variables. Clinical variables with a $p$-value $<0.1$ in univariable analysis were considered for multivariable analysis. The multivariable regression analysis was conducted by manual forward stepwise selection, and variables with a $p$-value $<0.05$ were retained.

All parametric data were presented as mean \pm standard deviation (SD) and nonparametric data as percentage (\%) or odds ratio (OR) with a 95\% confidence interval (95\% CI). All $p$-values are two-tailed, and $p$-values $<0.05$ were considered statistically significant. Statistical analyses were performed using SPSS version 22.0. (IBM Corp., Armonk, NY, USA). 


\section{Results}

A total of $258 \mathrm{CNCP}$ patients receiving LtOT, in six of eight hospitals, were included in the study (Figure 1). Patients from two hospitals were excluded due to delayed IRB approval. Based on the pre-defined consensus, 55 patients $(21 \%)$ were classified as OrCC.

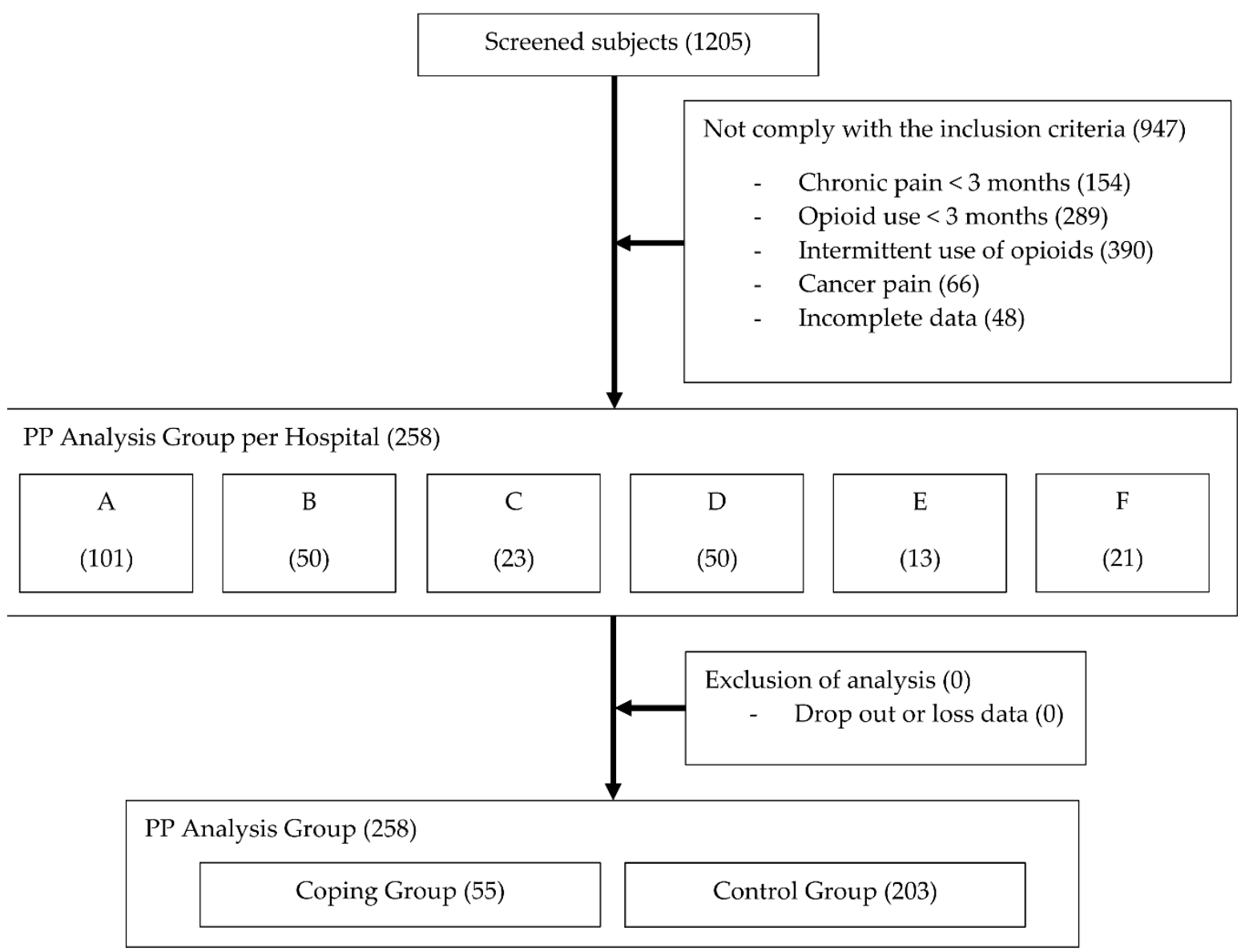

Figure 1. Flow diagram of participants. A, B, C, etc., indicate the hospitals that participated in the study. PP, per-protocol.

The patients were divided into two groups according to a positive OrCC (the coping group $(n=55)$ and control group $(n=203))$. Table 2 demonstrates the patients' sociodemographic data and clinical characteristics. The sample was homogenous in terms of ethnicity, sex, BMI, marital status, employment, and religion. The average pain duration was 74.55 months (95\% CI: $66.68-82.43$ ). When compared to the control group, patients in the coping group were younger (48.58 $\pm 12.25 \mathrm{vs}$. $53.79 \pm 13.54 ; p=0.038$ ) and with an education level greater or equal to high school level (90.9\% vs. $73.9 \% ; p=0.007)$. Although the reduction of NRS pain score from the initial to final visit was significant within each group ( $p<0.001$ in controls and $p=0.048$ in copers), it was less than 1 point in both groups. Pain in the head and neck, functional pain syndrome, and mixed pain were more common in copers $(27.3 \%$ vs. $13.3 \%, p=0.013 ; 18.2 \%$ vs. $2.5 \%, p<0.001$; and $18.2 \%$ vs. $8.4 \%$, $p=0.035$, respectively). Alcohol and/or medication abuse, and prescription drug use with alcohol within one year, were remarkably frequent in copers when compared to non-copers ( $20.0 \%$ vs. $3.9 \%$, $p<0.001 ; 9.1 \%$ vs. $0.5 \%, p<0.001$; and $22.6 \%$ vs. $8.5 \%, p=0.02$, respectively). More copers had co-morbid depression ( $50.9 \%$ vs. $27.6 \%, p=0.001)$ and reported ongoing litigation $(27.8 \%$ vs. $13.9 \%$, $p=0.010)$. Additionally, an overwhelming $66.7 \%$ of the sample $(n=172)$ had suicidal ideation related to their chronic pain. 
Table 2. Demographic variables and clinical characteristics.

\begin{tabular}{|c|c|c|c|c|}
\hline Variable & $\begin{array}{c}\text { Overall } \\
(n=258)\end{array}$ & $\begin{array}{l}\text { Control } \\
(n=203)\end{array}$ & $\begin{array}{l}\text { Coping* } \\
(n=55)\end{array}$ & $p$-Value \\
\hline Gender, $n(\%)$ & & & & 0.905 \\
\hline Male & $153(59.3)$ & $120(59.1)$ & $33(60.0)$ & \\
\hline Female & $105(40.7)$ & $83(40.9)$ & $22(40.0)$ & \\
\hline Age, mean \pm SD, years & $52.89 \pm 3.36$ & $53.79 \pm 13.54$ & $48.58 \pm 12.25$ & 0.038 \\
\hline Ethnicity, $n(\%)$, Asian & $258(100)$ & $203(78.7)$ & $55(21.3)$ & - \\
\hline $\mathrm{BMI}$, mean $\pm \mathrm{SD}, \mathrm{kg} / \mathrm{m}^{2}$ & $24.81 \pm 4.03$ & $24.89 \pm 3.87$ & $24.51 \pm 4.58$ & 0.544 \\
\hline Marital status, $n(\%)$ & & & & 0.960 \\
\hline Married & 64 (24.9) & $50(24.8)$ & $14(25.5)$ & \\
\hline Single & $185(72.0)$ & $146(72.3)$ & $39(70.9)$ & \\
\hline Divorced/Widowed & $8(3.1)$ & $6(3.0)$ & $2(3.6)$ & \\
\hline Education level, $n(\%)$ & & & & 0.007 \\
\hline$<$ high school & $58(22.6)$ & $53(26.1)$ & $5(9.1)$ & \\
\hline$\geq$ high school & $200(77.5)$ & $150(73.9)$ & $50(90.9)$ & \\
\hline Employment status, $n(\%)$ & & & & 0.982 \\
\hline $\begin{array}{l}\text { Unemployed (students and } \\
\text { housewives included) }\end{array}$ & $192(75.6)$ & $152(75.6)$ & $40(75.5)$ & \\
\hline Employed & $62(24.4)$ & $49(24.4)$ & $13(24.5)$ & \\
\hline Religion, $n(\%)$ & & & & 0.245 \\
\hline No & $130(50.6)$ & $106(52.5)$ & $24(43.6)$ & \\
\hline Yes & $127(49.4)$ & $96(47.5)$ & $31(56.4)$ & \\
\hline Chronicity of pain, mean \pm SD, months & $74.55 \pm 64.25$ & $73.23 \pm 66.09$ & $79.44 \pm 57.23$ & 0.526 \\
\hline \multicolumn{5}{|l|}{ NRS, mean \pm SD, points } \\
\hline Initial & $7.38 \pm 1.61$ & $7.37 \pm 1.54$ & $7.43 \pm 1.89$ & 0.730 \\
\hline Current & $6.55 \pm 2.09$ & $6.51 \pm 2.10$ & $6.86 \pm 2.07$ & 0.309 \\
\hline Absolute change & $-0.83 \pm 2.29$ & $-0.89 \pm 2.41$ & $-0.58 \pm 1.74$ & 0.364 \\
\hline$p$-value of absolute change & $<0.001$ & $<0.001$ & 0.048 & \\
\hline Percent change & $-8.6 \pm 32.3$ & $-8.9 \pm 22.1$ & $-8.5 \pm 34.4$ & $0.936^{\dagger}$ \\
\hline \multicolumn{5}{|l|}{ Etiology of pain, $n(\%)$} \\
\hline Trauma & $128(49.6)$ & $96(47.3)$ & $32(58.2)$ & 0.152 \\
\hline Surgery & $51(19.8)$ & $43(21.2)$ & $8(14.5)$ & 0.273 \\
\hline Degenerative & $15(5.8)$ & $10(4.9)$ & $5(9.1)$ & $0.325 \ddagger$ \\
\hline Disease & $73(26.7)$ & $56(28.1)$ & $17(32.7)$ & 0.236 \\
\hline Combined & $1(0.4)$ & $1(0.5)$ & $0(0.0)$ & 1 \\
\hline Idiopathic & $9(3.5)$ & $6(3.0)$ & $3(5.5)$ & $0.407 \ddagger$ \\
\hline \multicolumn{5}{|l|}{ Location of pain, $n(\%)$} \\
\hline Head and Neck & $42(16.3)$ & $27(13.3)$ & $15(27.3)$ & 0.013 \\
\hline Chest or Abdomen & $35(13.6)$ & $24(11.8)$ & $11(20.0)$ & 0.116 \\
\hline Back & $102(39.5)$ & $77(37.9)$ & $25(45.5)$ & 0.311 \\
\hline Extremities & $197(76.4)$ & $155(76.4)$ & $42(76.4)$ & 0.999 \\
\hline Others ${ }^{\S}$ or unknown & $20(7.8)$ & $15(7.4)$ & $5(9.1)$ & 0.776 \\
\hline \multicolumn{5}{|l|}{ Type of pain, $n(\%)$} \\
\hline Nociceptive & $36(14.0)$ & $29(14.3)$ & $7(12.7)$ & 0.767 \\
\hline Neuropathic & $197(76.4)$ & $160(78.8)$ & $37(67.3)$ & 0.074 \\
\hline Functional & $15(5.8)$ & $5(2.5)$ & $10(18.2)$ & $<0.001 \ddagger$ \\
\hline Mixed & $27(10.5)$ & $17(8.4)$ & $10(18.2)$ & 0.035 \\
\hline \multicolumn{5}{|l|}{ Substance abuse history within 1 year, $n(\%)$} \\
\hline Yes & $79(30.6)$ & $52(25.6)$ & $27(49.1)$ & 0.001 \\
\hline Tobacco & $62(24.0)$ & 46 (22.7) & $16(29.1)$ & 0.322 \\
\hline Alcohol & $19(7.4)$ & $8(3.9)$ & $11(20.0)$ & $<0.001$ \\
\hline Medication & $6(2.3)$ & $1(0.5)$ & $5(9.1)$ & $<0.001$ \\
\hline Illicit drugs & $0(0.0)$ & $0(0.0)$ & $0(0.0)$ & - \\
\hline Multiple & $1(0.4)$ & $1(0.5)$ & $0(0.0)$ & $1.00 \ddagger$ \\
\hline $\begin{array}{l}\text { Taken prescription drugs with alcohol within } \\
\qquad 1 \text { year, } n(\%)\end{array}$ & 29 (11.2) & $17(8.5)$ & $12(22.6)$ & 0.002 \\
\hline
\end{tabular}


Table 2. Cont.

\begin{tabular}{|c|c|c|c|c|}
\hline Variable & $\begin{array}{c}\text { Overall } \\
(n=258)\end{array}$ & $\begin{array}{c}\text { Control } \\
(n=203)\end{array}$ & $\begin{array}{l}\text { Coping * } \\
(n=55)\end{array}$ & $p$-Value \\
\hline \multicolumn{5}{|c|}{ Concurrent psychopathology, $n(\%)$} \\
\hline Yes & $120(46.5)$ & $86(42.4)$ & $34(61.8)$ & 0.008 \\
\hline Depression & $84(32.6)$ & $56(27.6)$ & $28(50.9)$ & 0.001 \\
\hline Anxiety & $25(9.7)$ & $19(9.4)$ & $6(10.9)$ & 0.73 \\
\hline PTSD & $52(20.2)$ & $37(18.2)$ & $15(27.3)$ & 0.138 \\
\hline Bipolar disorder & $6(2.3)$ & $4(2.0)$ & $2(3.6)$ & $0.611 \ddagger$ \\
\hline Others & $22(8.5)$ & $18(8.9)$ & $4(7.3)$ & $1.00 \ddagger$ \\
\hline \multicolumn{5}{|l|}{ Secondary morbid gain, $n(\%)$} \\
\hline Miss work or studies & & $30(83.3)$ & $12(92.3)$ & 0.658 \\
\hline Avoid military duty & $42(53.1)$ & $46(22.8)$ & $7(13.0)$ & 0.157 \\
\hline Ongoing litigation & $43(16.7)$ & $28(13.9)$ & $15(27.8)$ & 0.010 \\
\hline Suicidal ideation, $n(\%)$ & $172(66.7)$ & $132(65.3)$ & $40(75.5)$ & 0.161 \\
\hline
\end{tabular}

* The presence of OrCC was evaluated by a physician, using a questionnaire that contained seven behaviors related to OrCC. Two or more affirmative answers to the questionnaire were considered positive for OrCC. ${ }^{+}$Values from Mann-Whitney U test. $\ddagger$ Values from Fisher’s exact test. $§$ Whole body or genitalia. BMI, body mass index; NRS, numerical rating scale; PTSD, post-traumatic stress disorder; SD, standard deviation.

The opioid information is shown in Table 3. The duration of opioid administration and number of patients with co-prescription (including benzodiazepines) was not significantly different between groups. Although the opioid types (long-acting vs. short-acting) were similar in both groups, rapid-onset fentanyl and intravenous injections were more frequent in the coping group $(14.5 \%$ vs. $3.4 \%, p=0.005$ and $10.9 \%$ vs. $3.0 \%, p=0.023$, respectively). The average MEDD (mg/day) was significantly higher in the copers than the non-copers (169 \pm 186 vs. $119 \pm 227, p=0.006)$. Patients with MEDD $\geq 100$ and $\geq 200 \mathrm{mg}$ /day were more frequent in the coping group $(32.7 \% \mathrm{vs}$. $21.2 \%, p=0.033$ and $25.5 \%$ vs. $9.9 \%, p=0.002$, respectively). The number of annual visits to an opioid prescriber and the number of patients who visited the ER seeking for opioids was significantly higher in the copers than non-copers ( $36.35 \pm 53.93$ vs. $19.07 \pm 18.86$ visits, $p=0.023$ and $27.3 \%$ vs. $4.4 \%$, $p<0.001$, respectively). The first opioid prescriber was not significantly different between groups; and in $81 \%$ of the sample, the first opioid prescriber was a pain specialist.

Table 3. Opioid-related information.

\begin{tabular}{|c|c|c|c|c|}
\hline Variable & $\begin{array}{l}\text { Overall } \\
(n=258)\end{array}$ & $\begin{array}{l}\text { Control } \\
(n=203)\end{array}$ & $\begin{array}{l}\text { Coping * } \\
(n=55)\end{array}$ & $p$-Value \\
\hline Duration of opioids, mean $\pm \mathrm{SD}$, months & $16.34 \pm 31.08$ & $15.90 \pm 28.76$ & $17.85 \pm 38.25$ & 0.722 \\
\hline$>12$ months, $n(\%)$ & $65(25.2)$ & $51(25.1)$ & $14(25.5)$ & 0.747 \\
\hline \multicolumn{5}{|l|}{ Opioid types, $n(\%)$} \\
\hline Long-acting & $231(89.5)$ & $184(90.6)$ & $47(85.5)$ & 0.265 \\
\hline Oral long-acting & $213(82.6)$ & $170(83.7)$ & $43(78.2)$ & 0.335 \\
\hline Transdermal patch & $85(32.9)$ & $63(31.0)$ & $22(40.0)$ & 0.210 \\
\hline Short-acting & $145(56.2)$ & $109(53.7)$ & $36(65.5)$ & 0.119 \\
\hline Oral short-acting & $141(54.7)$ & $107(52.7)$ & $34(61.8)$ & 0.229 \\
\hline Rapid onset fentanyl & $15(5.8)$ & $7(3.4)$ & $8(14.5)$ & 0.005 \\
\hline Intravenous & $12(4.7)$ & $6(3.0)$ & $6(10.9)$ & 0.023 \\
\hline $\mathrm{MEDD}$, mean $\pm \mathrm{SD}, \mathrm{mg} /$ day & $129 \pm 220$ & $119 \pm 227$ & $169 \pm 186$ & $0.006^{\dagger}$ \\
\hline$\geq 100 \mathrm{mg} /$ day, $n(\%)$ & $95(36.8)$ & $68(33.5)$ & $27(49.1)$ & 0.033 \\
\hline$\geq 200 \mathrm{mg} /$ day, $n(\%)$ & $34(13.2)$ & $20(9.9)$ & $14(25.5)$ & 0.002 \\
\hline $\begin{array}{l}\text { Number of visits per year to the opioid } \\
\text { provider, mean } \pm \text { SD }\end{array}$ & $22.77 \pm 30.71$ & $19.07 \pm 18.86$ & $36.35 \pm 53.93$ & 0.023 \\
\hline ER visits seeking opioids, $n(\%)$ & $24(9.3)$ & $9(4.4)$ & $15(27.3)$ & $<0.001$ \\
\hline
\end{tabular}


Table 3. Cont.

\begin{tabular}{|c|c|c|c|c|}
\hline Variable & $\begin{array}{c}\text { Overall } \\
(n=258)\end{array}$ & $\begin{array}{c}\text { Control } \\
(n=203)\end{array}$ & $\begin{array}{l}\text { Coping * } \\
(n=55)\end{array}$ & $p$-Value \\
\hline First opioid provider, $n(\%)$ & & & & 0.702 \\
\hline Family doctor & $2(0.8)$ & $1(0.5)$ & $1(1.8)$ & 0.609 \\
\hline General physician & $6(2.3)$ & $5(2.5)$ & $1(1.8)$ & 0.778 \\
\hline Surgeon & $20(7.8)$ & $13(6.4)$ & $7(12.7)$ & 0.120 \\
\hline ER physician & $2(0.8)$ & $2(1.0)$ & $0(0.0)$ & 0.460 \\
\hline Pain physician & $209(81.0)$ & $166(81.8)$ & $43(78.2)$ & 0.547 \\
\hline Others $\ddagger$ & $18(7.0)$ & $15(7.4)$ & $3(5.5)$ & 0.617 \\
\hline Unknown & $1(0.4)$ & $1(0.5)$ & $0(0.0)$ & 0.602 \\
\hline Benzodiazepines, $n(\%)$ & $120(46.5)$ & $95(46.8)$ & $25(45.5)$ & 0.859 \\
\hline Non-opioid medications, $n(\%)$ & & & $<$ & \\
\hline Antidepressants & $134(51.9)$ & $107(55.4)$ & $27(51.9)$ & 0.651 \\
\hline Anticonvulsants & $182(70.5)$ & $149(77.2)$ & $33(64.7)$ & 0.068 \\
\hline Topical agents & $33(12.8)$ & $24(12.4)$ & $9(17.6)$ & 0.333 \\
\hline Physical therapy, $n(\%)$ & $32(12.4)$ & $28(3.9)$ & $4(7.4)$ & 0.203 \\
\hline
\end{tabular}

* The presence of OrCC was evaluated by a physician, using a questionnaire that contained seven behaviors related to OrCC. Two or more affirmative answers to the questionnaire were considered positive for OrCC. † Values from Mann-Whitney U test. $\ddagger$ Gynecology, internal medicine, neurology, neuropsychiatry, orthopedics, otorhinolaryngology. ER, emergency room; MEDD, morphine equivalent daily dose; SD, standard deviation.

Table 4 shows the questionnaires and predictive tools used in the study. Although the proportion of patients with a positive CAGE-AID was higher in the copers $(80.0 \%$ vs. $66.5 \%)$, it did not reach statistical significance $(p=0.054)$. The PCS was over 30 in both groups, indicating a "catastrophic" appraisal of pain. The "worst" NRS item of the BPI-SF was higher, and the general activity, mood, and sleep interference were worse in the copers than the non-copers $(p=0.001, p=0.043, p=0.013$, and $p=0.021$, respectively). The K-IADL score and percentages were higher in the coping group $(p=0.031$ and $p=0.017$, respectively). Both groups reported high anxiety and depression in HADS, moderate clinical insomnia in the ISI, and low resilience in the K-CD-RISC.

Table 4. Questionnaires and predictive tools.

\begin{tabular}{|c|c|c|c|c|}
\hline Variable & $\begin{array}{c}\text { Overall } \\
(n=258)\end{array}$ & $\begin{array}{c}\text { Control } \\
(n=203)\end{array}$ & $\begin{array}{l}\text { Coping * } \\
(n=55)\end{array}$ & $p$-Value \\
\hline \multicolumn{5}{|l|}{ CAGE-AID, $n(\%)$} \\
\hline Negative & 79 (30.6) & $68(33.5)$ & $11(20.0)$ & 0.106 \\
\hline Positive ( $\geq 1$ positive) & $179(69.4)$ & $135(66.5)$ & $44(80.0)$ & 0.054 \\
\hline $\mathrm{PCS}$, mean $\pm \mathrm{SD}$, points & $34.22 \pm 12.27$ & $34.14 \pm 12.33$ & $34.51 \pm 12.18$ & 0.843 \\
\hline$\geq 30$ points, $n(\%)$ & 170 (65.9) & $134(66.0)$ & $36(65.5)$ & 0.939 \\
\hline \multicolumn{5}{|l|}{ BPI-SF, mean $\pm S D$, points } \\
\hline Worst NRS & $8.12 \pm 1.97$ & $7.95 \pm 2.06$ & $8.75 \pm 1.42$ & 0.001 \\
\hline NRS on average & $6.63 \pm 2.05$ & $6.53 \pm 2.05$ & $6.98 \pm 2.04$ & 0.152 \\
\hline NRS right now & $6.37 \pm 2.36$ & $6.29 \pm 2.30$ & $6.67 \pm 2.58$ & 0.288 \\
\hline Pain relief (\%) & $48.44 \pm 23.47$ & $49.79 \pm 22.39$ & $43.45 \pm 26.75$ & 0.112 \\
\hline \multicolumn{5}{|l|}{ Pain interference } \\
\hline General activity & $6.47 \pm 2.48$ & $6.31 \pm 2.53$ & $7.07 \pm 2.20$ & 0.043 \\
\hline Mood & $6.59 \pm 2.53$ & $6.39 \pm 2.56$ & $7.35 \pm 2.27$ & 0.013 \\
\hline Walking ability & $5.85 \pm 3.14$ & $5.77 \pm 3.14$ & $6.15 \pm 3.15$ & 0.437 \\
\hline Normal work & $6.38 \pm 2.75$ & $6.22 \pm 2.79$ & $6.96 \pm 2.55$ & 0.076 \\
\hline Relations with other people & $6.04 \pm 3.26$ & $5.88 \pm 3.28$ & $6.62 \pm 3.15$ & 0.137 \\
\hline Sleep & $6.29 \pm 3.09$ & $6.06 \pm 3.12$ & $7.15 \pm 2.85$ & 0.021 \\
\hline Enjoyment of life & $6.78 \pm 3.00$ & $6.66 \pm 3.03$ & $7.22 \pm 2.85$ & 0.221 \\
\hline $\mathrm{K}$-IADL, mean $\pm \mathrm{SD}$, points & $7.46 \pm 7.18$ & $6.96 \pm 6.90$ & $9.31 \pm 7.90$ & 0.031 \\
\hline Percentage & $64.01 \pm 74.55$ & $58.28 \pm 73.74$ & $85.18 \pm 74.35$ & 0.017 \\
\hline PGIC, $n(\%)$, better & $108(41.9)$ & $89(43.8)$ & $19(34.5)$ & 0.215 \\
\hline Satisfaction scale, $^{+}$ & & & & 0.002 \\
\hline Satisfied, $n(\%)$ & $190(73.6)$ & $159(78.3)$ & $31(56.4)$ & \\
\hline Unsatisfied, $n(\%)$ & $68(26.4)$ & $44(21.7)$ & $24(43.6)$ & \\
\hline
\end{tabular}


Table 4. Cont.

\begin{tabular}{|c|c|c|c|c|}
\hline Variable & $\begin{array}{c}\text { Overall } \\
(n=258)\end{array}$ & $\begin{array}{c}\text { Control } \\
(n=203)\end{array}$ & $\begin{array}{l}\text { Coping * } \\
(n=55)\end{array}$ & $p$-Value \\
\hline \multicolumn{5}{|l|}{ HADS } \\
\hline Anxiety, mean $\pm S D$, points & $10.88 \pm 4.99$ & $10.72 \pm 4.80$ & $11.45 \pm 5.66$ & 0.381 \\
\hline$\geq 11$ (abnormal), $n(\%)$ & 125 (48.4) & $96(47.3)$ & $29(52.7)$ & 0.474 \\
\hline Depression, mean $\pm S D$, points & $11.76 \pm 4.71$ & $11.74 \pm 4.35$ & $11.80 \pm 5.91$ & 0.938 \\
\hline$\geq 11$ (abnormal), $n(\%)$ & $160(62.0)$ & $127(62.6)$ & $33(60.0)$ & 0.728 \\
\hline ISI, mean \pm SD, points & $16.83 \pm 7.63$ & $16.61 \pm 7.62$ & $17.62 \pm 7.66$ & 0.386 \\
\hline$\geq 15$ (moderate-severe), $n(\%)$ & $162(62.8)$ & $124(61.1)$ & $38(69.1)$ & 0.276 \\
\hline$\geq 22$ (severe),$n(\%)$ & $88(34.1)$ & $66(32.5)$ & $22(40.0)$ & 0.299 \\
\hline K-CD-RISC, mean \pm SD, points & $67.95 \pm 22.06$ & $68.77 \pm 22.24$ & $64.91 \pm 21.30$ & 0.250 \\
\hline
\end{tabular}

* The presence of OrCC was evaluated by a physician, using a questionnaire that contained seven behaviors related to OrCC. Two or more affirmative answers to the questionnaire were considered positive for OrCC. + Satisfied $=$ extremely satisfied and somewhat satisfied, unsatisfied = somewhat unsatisfied and extremely unsatisfied; BPI-SF, brief pain inventory-short form; CAGE-AID, cut down, annoyed, guilty, eye-opener-adapted to include drugs; HADS, hospital anxiety and depression scale; ISI, insomnia severity index; K-IADL, Korean-instrumental activities of daily living; K-CD-RISC, Korean-Connor-Davidson resilience scale; PCS, pain catastrophizing scale; PGIC, patient global impression of change; SD, standard deviation.

About $74 \%$ of the subjects were extremely or somewhat satisfied with their LtOT, and the percent of patients unsatisfied was significantly more prevalent among copers vs. non-copers ( $n=24,44 \% \mathrm{vs}$. $n=44,22 \% ; p=0.002$ ). The PGIC was similar in both groups. There were no differences in the adverse or undesirable effects between groups, and $62 \%$ of the patients reported at least one event. The most frequent was constipation $(n=105,40.7 \%)$ followed by somnolence $(n=62,24.0 \%)$ and nausea $(n=50$, $19.4 \%)$.

Figure 2 shows the independent predictors of OrCC identified in multivariable analysis. The risk of OrCC increased in patients with: (1) prescription drugs abuse (Odds ratio (OR) $=19.32(95 \%$ confidence interval $(\mathrm{CI})=1.75-213.81), p=0.016) ;(2)$ alcohol abuse $(\mathrm{OR}=6.84$ (95\% CI = 2.26-20.69), $p=0.001)$; (3) functional pain syndrome (OR = $12.96(3.47-48.45), p<0.001)$; (4) head and neck pain ( $\mathrm{OR}=2.48(95 \% \mathrm{CI}=1.05-5.88), p=0.039)$; (5) $\mathrm{MEDD} \geq 200 \mathrm{mg} /$ day $(\mathrm{OR}=3.48$ (95\% CI $=1.43-8.48), p=0.006)$; and (6) ongoing litigation ( $\mathrm{OR}=2.33(95 \% \mathrm{CI}=1.01-5.39) p=0.047)$. Additionally, age $<55$ years ( $\mathrm{OR}=2.17(95 \% \mathrm{CI}=0.99-4.76), p=0.052)$ and BPI-SF mood interference $\geq 8(\mathrm{OR}=1.84(95 \% \mathrm{CI}=0.90-3.77), p=0.096)$ remained in the multivariable model.

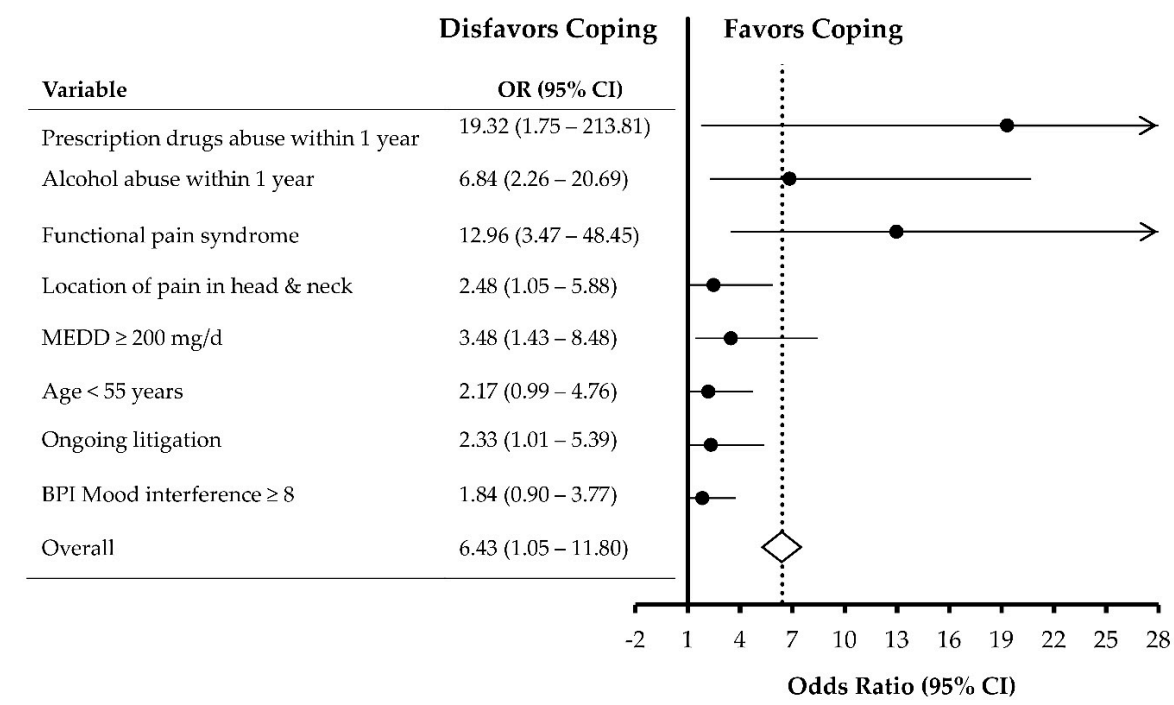

Figure 2. Forest plot of multivariable analysis showing the factors independently associated with opioid-related chemical coping. OR, odds ratio; CI, confidence interval; BPI, brief pain inventory; MEDD, morphine equivalent daily dose. 


\section{Discussion}

This study evaluated the rate of OrCC and patient characteristics in a group of CNCP patients receiving LtOT. The frequency of OrCC was $21 \%$, which indicates that about one out of every five $\mathrm{CNCP}$ patients used opioids to cope with emotional distress. There is a scarcity of research regarding the frequency of OrCC, with the except of one study [17] which reported a rate of $18 \%$ in palliative care patients in the U.S. Therefore, to the best of our knowledge, this is the first study to evaluate the rate of OrCC in CNCP. Our results demonstrate that the frequency of CNCP patients coping chemically with opioids is as high as that found in cancer patients [17]. Furthermore, it is comparable to the rate of misuse (21-29\%) determined in a recent systematic review that included 35 studies from the U.S. and three studies from the European Union (EU) [19]. Our results show that OrCC in CNCP is comparably high to OUD rates, even in countries with low-moderate opioid consumption.

Regarding patients' demographics, previous studies reported that young age and male sex are common risk factors for OUD and dependency [45,46]. In this study, although the copers were younger, patient sex was not statistically significant, which correlates with another OrCC study [17]. OrCC patients had high level of education compared to the non-copers, which contradicts previous studies in substance abuse and dependence $[47,48]$. The discrepancy in our finding may be explained as an interaction effect between age and level of education (correlation coefficient $=-0.178, p=0.005$ ). In our study, younger patients had higher level of education and conversely older patients had lower than high school education level. A recent report found that $66 \%$ of Koreans, between the age of 25 and 34 years, attained tertiary education, while only $8 \%$ of Korean women aged 55-64 years did it [49]. Therefore, younger patients with an increased liability to OrCC had higher education levels, which may explain our results.

In terms of the pain characteristics, the overall patients in this study complained of moderate to severe pain with the NRS pain score of $>7$ at their initial visits. Despite LtOT, however, their pain improvement on the last measurement was trivial with only $8.6 \%$ reduction in the pain severity. In addition, the prevalence of posttraumatic stress disorder in the study's sample was relatively high ( $n=52,20.2 \%$ ) without significant differences between the groups. Those patients have more risk factors for pain, including higher rates of psychiatric and substance use disorders [50], which may explain the high frequency of the disorder found in this study. Another interesting result in this study was that head and neck pain increased 2.5 times $(p=0.039)$, and functional pain disorders increased 13 times the risk of $\operatorname{OrCC}(p<0.001)$ in our multivariable analysis. Functional pain syndromes typically concur with anxiety, depression, and chronic fatigue syndrome [51], conditions for which opioids are usually ineffective [52]. Therefore, the treatment of chronic functional pain should be centered in non-opioid pharmacotherapy with active use of physiotherapeutic and psychological methods to improve coping with pain [53]. Moreover, patients receiving LtOT without improvement in the pain control should be evaluated to assess the real contribution of opioids and to reduce drug toxicity.

Major depression and alcohol or drug abuse are known risk factors for OUD and OrCC $[16,54,55]$ which is concordant with our result. Markou et al. [56] asserted that depression has neurobiological effects similar to those in alcohol or opiate withdrawal syndromes. Hence, patients with underlying depression may self-medicate with opioids to correct their dysfunctional systems. Our sample had high HADS scores without statistically significant differences between groups, which may be explained by the scale's low specificity $(\sim 50 \%)$ and sex/age-related biases [57], and due to the high prevalence of anxiety and depression in chronic pain patients with LtOT. In addition, alcohol and prescription drug abuse also increased $7(p=0.001)$ and 19 times $(p=0.016)$ the risk of OrCC in our results. The concomitant use of alcohol and opioids is associated with OUD, OrCC and worse outcomes [58], which is consistent with our result $(p=0.002)$. Therefore, CNCP patients with alcohol and/or prescription drug abuse history require special attention due to an increased risk of OrCC, opioid toxicity, and poor outcomes.

Similar to previous studies in OUD [59,60], patients with OrCC received significantly higher dosages of opioids $(p=0.006)$ in this study. Interestingly, doses of $100-200 \mathrm{mg} /$ day were not different 
among the groups $(p=0.878)$. However, dosages $\geq 200 \mathrm{mg} /$ day almost quadrupled the risk of OrCC $(p=0.002)$. Another study from the U.S. also found increased OUD rates with dosages $\geq 200 \mathrm{mg}$ /day, without differences at 100 or $120 \mathrm{mg} /$ day [61]. Therefore, dosages $\geq 200 \mathrm{mg} /$ day should be concerning in CNCP due to a high correlation with OrCC and OUD. In terms of opioid types, rapid-onset opioids (ROOs) were prescribed more frequently in the coping group. ROOs are used for the management of breakthrough pain (BTP) in opioid-tolerant patients with cancer or noncancer pain [62-64]. Although the evidence linking ROOs to OUD is limited [65,66], our results support that ROOs may potentiate OUD. A cautious use of ROOs in CNCP patients is recommended and further studies that evaluate its association with OUD are needed. Additionally, frequent visits to the provider and/or the ER seeking for opioids was correlated with $\operatorname{OrCC}(p=0.001$ and $p<0.001$ respectively). Therefore, although pseudo-addiction should be initially discarded as a cause of opioid seeking [67], frequent hospital and ER visitors must be evaluated for OUD.

The BPI-SF showed increased pain interference, and the K-IADL indicated an increased compromise of daily activities in the copers. Our results suggest that decreased functionality and high pain interference constitute risk factors of OrCC $[68,69]$. Ongoing litigation doubled the risk of OrCC. Although previous studies have not linked litigation with OUD, this process causes negative emotions that accentuate the underlying pain with anger, frustration, and helplessness [70], which may induce OrCC. Furthermore, two-thirds of the sample had catastrophic thinking and moderate-severe insomnia. Pain catastrophizing is associated with pain severity, altered CNS pain processing, and exaggerated pain-related interference [71]. Our sample had low resilience (68/100 points), compared to the U.S. general population average (80/100 points) [35]. These findings highlight the role of psychological therapy in improving pain-coping skills and functionality in CNCP patients [72,73].

Contrary to previous studies on chemical coping [17,67], in this study, the CAGE-AID questionnaire was not significantly positive in the OrCC group when compared to the controls $(p=0.054)$. Interestingly, CAGE-AID positives were found in $66.5 \%$ of the controls, whereas $20 \%$ negatives were copers. This result infers that CAGE-AID is a predictive, but not a diagnostic tool for OUD with a low specificity $[17,74]$. Moreover, the questionnaire focuses on addiction and may not detect risky use in non-dependent individuals [30], as in our study population. Another distinctive result is that pain specialists were the predominant opioid prescribers. S. Korea's strict regulations on opioids and the difficulties of storage and administration limit their use by primary specialists [75]. Conversely, in the U.S., the primary care specialty groups accounted for nearly half (44.5\%) of all dispensed opioid prescriptions during 2007-2012 [76]. Additionally, insufficient training in the management of CNCP and excessive focus on the treatment with opioids may lead to its over-prescription and the under-detection of OUD $[77,78]$. Accordingly, the mean amount of opioids prescribed per person in 2015 in the U.S. was $640 \mathrm{mg}$ /day (0.1-5543 mg/day) [2], almost five times the mean in our study $129 \mathrm{mg} /$ day $(4.5-2700 \mathrm{mg} /$ day).

Another remarkable finding in this study is the absence of illicit drug abuse reports. This result may be secondary to deep-rooted cultural and social stigmatization of illicit drugs in Asia [79]. Historically, S. Korea has been viewed as a drug-free country when compared to the U.S., Japan, and other countries [80]. Traditional drugs, including heroin and cocaine, are not commonly used in S. Korea, as reflected by drug seizure and arrest data [81]. Consequently, the laws that control illicit drug-use may influence the rates of overdose deaths in S. Korea.

There are several limitations to be addressed. First, this study took place only in tertiary hospitals. This may be associated with biases for generalization since the patients in this study may have more challenging pain syndromes than those in primary institutions. Second, the questionnaire used to evaluate OrCC was a result of an expert meeting, however, it is not a validated tool. In addition, although there were three consensus and educational meetings prior to patient enrollment, there might be detection biases between pain specialists. Nonetheless, OrCC is a clinical phenomenon accurately assessed by experienced providers [14], thus, a high predictability of true positives may be expected. Moreover, in this study, OrCC was evaluated immediately after each visit to avoid 
inappropriate scoring or recall biases. Third, our sample size was relatively large $(n=258)$; however, a broad $\mathrm{CI}$ of some OrCC risk factors in our multivariable analysis, such as prescription drug abuse $(\mathrm{OR}=19.32(95 \% \mathrm{CI}=1.75-213.81))$ or functional pain syndrome $(\mathrm{OR}=12.96(95 \% \mathrm{CI}=3.47-48.45))$, would be a limitation. Another drawback is that the study's data depended on statements from patients. Although there was assurance of confidentiality, patients' responses may not always be reliable. Finally, urine drug test (UDT) and opiate immunoassay, which are considered "gold standards" to assess OUD [7], were not conducted. Barriers to cost-effectiveness and accessibility restricted their use in this study.

\section{Conclusions}

Approximately $21 \%$ of the CNCP patients receiving LtOT are chemically coping with opioids, carrying high intensity of pain, and experiencing severe interference in daily activities. The high rates of OrCC found in this study suggest that the break-out of OUD in CNCP of S. Korea is comparable to those in countries with high opioid consumption, such as the U.S., regardless of the country's opioid consumption rates. Therefore, we should be vigilant about OUD in CNCP patients with LtOT. The independent risk factors of OrCC are prescription drugs and alcohol abuse, functional pain syndrome, pain in the head and neck, MEDD $\geq 200 \mathrm{mg} /$ day, and ongoing litigation. Although further validation studies are warranted, the assessment of OrCC may prompt the identification of patients at high risk for severe OUD. Finally, although our result has suggested that there is no benefit of LtOT in $\mathrm{CNCP}$, more research is needed to establish the rationale of evidence-based opioid prescription that should be limited to short-term use as much as possible.

Author Contributions: Conceptualization, A.M.C. and J.Y.M.; methodology, J.Y.M. and A.M.C.; software, D.L. and C.-S.L.; validation, Y.-C.K. and J.Y.M.; formal analysis, C.-S.L., D.L. and A.M.C.; investigation, A.M.C. and J.Y.M.; resources, Y.-C.K. and J.Y.M.; data curation, D.L. and C.-S.L.; writing-original draft preparation, A.M.C.; writing-review and editing, J.Y.M. and A.M.C.; visualization, J.Y.M. and A.M.C.; supervision, Y.-C.K. and J.Y.M.; project administration, Y.-C.K.; and funding acquisition, J.Y.M.

Funding: This research was funded by Pharmbio Korea Inc., Seoul, South Korea.

Acknowledgments: We want to thank Eun-Joo Choi, Won-Joong Kim, Jong Bum Choi, Jae Hun Kim, Hwa-Yong Shin, Young Hoon Kim, and Jung Eun Kim for their participation in assessing chemical coping at their respective hospitals. Special thanks to Jung Hye Kwon for her valuable guidance and contribution as an expert in opioid-related chemical coping.

Conflicts of Interest: The authors declare no conflicts of interests with respect to this research, authorship, and/or publication of the article. The funding agency had no role in the design of the study; the collection, execution, analyses, or interpretation of the data; in the writing of the manuscript, or in the decision to publish the results.

\section{References}

1. Brennan, F.; Cousins, M.J. Pain Relief as a Human Right. Pain Clin. Updat. 2004, 12, 1-4.

2. Centers for Disease Control and Prevention. Opioid Prescribing 2017. Available online: https://www.cdc. gov/vitalsigns/opioids/index.html (accessed on 12 May 2018).

3. Krnic, D.; Anic-Matic, A.; Dosenovic, S.; Draganic, P.; Zezelic, S.; Puljak, L. National consumption of opioid and nonopioid analgesics in Croatia: 2007-2013. Ther. Clin. Risk Manag. 2015, 11, 1305-1314. [CrossRef] [PubMed]

4. Pain \& Policy Studies Group. Opioid Consumption Data 2017. Available online: http:/ /www.painpolicy. wisc.edu/opioid-consumption-data (accessed on 11 May 2018).

5. Duthey, B.; Scholten, W. Adequacy of opioid analgesic consumption at country, global, and regional levels in 2010, its relationship with development level, and changes compared with 2006. J. Pain Symptom Manag. 2014, 47, 283-297. [CrossRef] [PubMed]

6. Le Merrer, J.; Becker, J.A.; Befort, K.; Kieffer, B.L. Reward processing by the opioid system in the brain. Physiol. Rev. 2009, 89, 1379-1412. [CrossRef] [PubMed] 
7. Chou, R.; Turner, J.A.; Devine, E.B.; Hansen, R.N.; Sullivan, S.D.; Blazina, I.; Dana, T.; Bougatsos, C.; Deyo, R.A. The effectiveness and risks of long-term opioid therapy for chronic pain: A systematic review for a National Institutes of Health Pathways to Prevention Workshop. Ann. Intern. Med. 2015, 162, 276-286. [CrossRef] [PubMed]

8. $\quad$ Chung, S.S.; Park, C.K.; Cho, K.J.; Choi, K.H.; Kim, J.H.; Kim, S.B.; Kuh, S.U.; Lee, J.C.; Lee, J.H.; Lee, K.Y.; et al. A Nationwide Retrospective Study of Opioid Management Patterns in 2,468 Patients with Spinal Pain in Korea. Asian Spine J. 2016, 10, 1122-1131. [CrossRef] [PubMed]

9. Krebs, E.E.; Gravely, A.; Nugent, S.; Jensen, A.C.; DeRonne, B.; Goldsmith, E.S.; Kroenke, K.; Bair, M.J.; Noorbaloochi, S. Effect of Opioid vs. Nonopioid Medications on Pain-Related Function in Patients with Chronic Back Pain or Hip or Knee Osteoarthritis Pain: The SPACE Randomized Clinical Trial. JAMA 2018, 319, 872-882. [CrossRef] [PubMed]

10. Ray, W.A.; Chung, C.P.; Murray, K.T.; Hall, K.; Stein, C.M. Prescription of Long-Acting Opioids and Mortality in Patients with Chronic Noncancer Pain. JAMA 2016, 315, 2415-2423. [CrossRef] [PubMed]

11. Kirsh, K.L.; Jass, C.; Bennett, D.S.; Hagen, J.E.; Passik, S.D. Initial development of a survey tool to detect issues of chemical coping in chronic pain patients. Palliat. Support. Care 2007, 5, 219-226. [CrossRef] [PubMed]

12. Kwon, J.H.; Hui, D.; Bruera, E. A Pilot Study to Define Chemical Coping in Cancer Patients Using the Delphi Method. J. Palliat. Med. 2015, 18, 703-706. [CrossRef] [PubMed]

13. Volkow, N.D.; Koob, G.F.; McLellan, A.T. Neurobiologic Advances from the Brain Disease Model of Addiction. N. Engl. J. Med. 2016, 374, 363-371. [CrossRef] [PubMed]

14. Bruera, E.; Schoeller, T.; Wenk, R.; MacEachern, T.; Marcelino, S.; Hanson, J.; Suarez-Almazor, M. A prospective multicenter assessment of the Edmonton staging system for cancer pain. J. Pain Symptom Manag. 1995, 10, 348-355. [CrossRef]

15. Nikulina, V.; Guarino, H.; Acosta, M.C.; Marsch, L.A.; Syckes, C.; Moore, S.K.; Portenoy, R.K.; Cruciani, R.A.; Turk, D.C.; Rosenblum, A. Patient vs. provider reports of aberrant medication-taking behavior among opioid-treated patients with chronic pain who report misusing opioid medication. Pain 2016, 157, 1791-1798. [CrossRef] [PubMed]

16. Del Fabbro, E. Assessment and management of chemical coping in patients with cancer. J. Clin. Oncol. 2014, 32, 1734-1738. [CrossRef] [PubMed]

17. Kwon, J.H.; Tanco, K.; Park, J.C.; Wong, A.; Seo, L.; Liu, D.; Chisholm, G.; Williams, J.; Hui, D.; Bruera, E. Frequency, Predictors, and Medical Record Documentation of Chemical Coping Among Advanced Cancer Patients. Oncologist 2015, 20, 692-697. [CrossRef] [PubMed]

18. Voon, P.; Karamouzian, M.; Kerr, T. Chronic pain and opioid misuse: A review of reviews. Subst. Abuse Treat Prev. Policy 2017, 12, 36. [CrossRef] [PubMed]

19. Vowles, K.E.; McEntee, M.L.; Julnes, P.S.; Frohe, T.; Ney, J.P.; van der Goes, D.N. Rates of opioid misuse, abuse, and addiction in chronic pain: A systematic review and data synthesis. Pain 2015, 156, 569-576. [CrossRef] [PubMed]

20. Green, C.R.; Anderson, K.O.; Baker, T.A.; Campbell, L.C.; Decker, S.; Fillingim, R.B.; Kalauokalani, D.A.; Lasch, K.E.; Myers, C.; Tait, R.C.; et al. The unequal burden of pain: Confronting racial and ethnic disparities in pain. Pain Med. 2003, 4, 277-294. [CrossRef] [PubMed]

21. Kroenke, K.; Cheville, A. Management of Chronic Pain in the Aftermath of the Opioid Backlash. JAMA 2017, 317, 2365-2366. [CrossRef] [PubMed]

22. Coleman, J.J. The supply chain of medicinal controlled substances: Addressing the Achilles heel of drug diversion. J. Pain Palliat. Care Pharmacother. 2012, 26, 233-250. [CrossRef] [PubMed]

23. Hall, A.J.; Logan, J.E.; Toblin, R.L.; Kaplan, J.A.; Kraner, J.C.; Bixler, D.; Crosby, A.E.; Paulozzi, L.J. Patterns of abuse among unintentional pharmaceutical overdose fatalities. JAMA 2008, 300, 2613-2620. [CrossRef] [PubMed]

24. O’Brien, T.; Christrup, L.L.; Drewes, A.M.; Fallon, M.T.; Kress, H.G.; McQuay, H.J.; Mikus, G.; Morlion., B.J.; Perez-Cajaraville, J.; Pogatzki-Zahn, E.; et al. European Pain Federation position paper on appropriate opioid use in chronic pain management. Eur. J. Pain 2017, 21, 3-19. [CrossRef]

25. Von Elm, E.; Altman, D.G.; Egger, M.; Pocock, S.J.; Gøtzsche, P.C.; Vandenbroucke, J.P.; STROBE Initiative. Strengthening the reporting of observational studies in epidemiology (STROBE) statement: Guidelines for reporting observational studies. BMJ 2007, 335, 806-808. [CrossRef] [PubMed] 
26. Treede, R.D.; Rief, W.; Barke, A.; Aziz, Q.; Bennett, M.I.; Benoliel, R.; Cohen, M.; Evers, S.; Finnerup, N.B.; First, M.B.; et al. A classification of chronic pain for ICD-11. Pain 2015, 156, 1003-1007. [CrossRef] [PubMed]

27. American Psychiatric Association. Diagnostic and Statistical Manual of Mental Disorders (DSM-5), 5th ed.; American Psychiatric Publishing: Washington, DC, USA, 2013; p. 541. ISBN 13:978-0890425558.

28. Carlsson, A.M. Assessment of chronic pain. I. Aspects of the reliability and validity of the visual analogue scale. Pain 1983, 16, 87-101. [CrossRef]

29. National Center for Injury Prevention and Control. CDC Compilation of Benzodiazepines, Muscle Relaxants, Stimulants, Zolpidem, and Opioid Analgesics with Oral Morphine Milligram Equivalent Conversion Factors; Centers for Disease Control and Prevention: Atlanta, GA, USA, 2016; Grant No. 2010-DG-BX-K088; Available online: http://www.pdmpassist.org/pdf/BJA_performance_measure_aid_MME_conversion.pdf (accessed on 11 May 2018).

30. Brown, R.L.; Rounds, L.A. Conjoint screening questionnaires for alcohol and other drug abuse: Criterion validity in a primary care practice. Wis. Med. J. 1995, 94, 135-140. [PubMed]

31. Yun, Y.H.; Mendoza, T.R.; Heo, D.S.; Yoo, T.; Heo, B.Y.; Park, H.A.; Shin, H.C.; Wang, X.S.; Cleeland, C.S. Development of a cancer pain assessment tool in Korea: A validation study of a Korean version of the brief pain inventory. Oncology 2004, 66, 439-444. [CrossRef] [PubMed]

32. Sullivan, M.J.L.; Bishop, S.R.; Pivik, J. The Pain Catastrophizing Scale: Development and validation. Psychol. Assess 1995, 7, 524-532. [CrossRef]

33. Zigmond, A.S.; Snaith, R.P. The hospital anxiety and depression scale. Acta Psychiatr. Scand. 1983, 67, 361-370. [CrossRef] [PubMed]

34. Bastien, C.H.; Vallieres, A.; Morin, C.M. Validation of the Insomnia Severity Index as an outcome measure for insomnia research. Sleep Med. 2001, 2, 297-307. [CrossRef]

35. Won, C.W.; Rho, Y.G.; SunWoo, D.; Lee, Y.S. The Validity and Reliability of Korean Instrumental Activities of Daily Living (K-IADL) Scale. J. Korean Geriatr. Soc. 2002, 6, 273-280.

36. Connor, K.M.; Davidson, J.R. Development of a new resilience scale: The Connor-Davidson Resilience Scale (CD-RISC). Depress. Anxiety 2003, 18, 76-82. [CrossRef] [PubMed]

37. Hurst, H.; Bolton, J. Assessing the clinical significance of change scores recorded on subjective outcome measures. J. Manip. Physiol. Ther. 2004, 27, 26-35. [CrossRef] [PubMed]

38. Jovey, R.D. Opioids, pain, and addiction-practical strategies. Br. J. Pain 2012, 6, 36-42. [CrossRef] [PubMed]

39. Atkinson, T.M.; Mendoza, T.R.; Sit, L.; Passik, S.; Scher, H.I.; Cleeland, C.; Basch, E. The Brief Pain Inventory and its "pain at its worst in the last $24 \mathrm{~h}$ " item: Clinical trial endpoint considerations. Pain Med. 2010, 11,337-346. [CrossRef] [PubMed]

40. Stern, A.F. The hospital anxiety and depression scale. Occup. Med. 2014, 64, 393-394. [CrossRef] [PubMed]

41. Morin, C.M.; Belleville, G.; Belanger, L.; Ivers, H. The Insomnia Severity Index: Psychometric indicators to detect insomnia cases and evaluate treatment response. Sleep 2011, 34, 601-608. [CrossRef] [PubMed]

42. Kang, S.J.; Choi, S.H.; Lee, B.H.; Kwon, J.C.; Na, D.L.; Han, S.H. The Reliability and Validity of the Korean Instrumental Activities of Daily Living (K-IADL). J. Korean Neurol. Assoc. 2002, 20, 8-14.

43. Jung, Y.E.; Min, J.A.; Shin, A.Y.; Han, S.Y.; Lee, K.U.; Kim, T.S.; Park, J.E.; Choi, S.W.; Lee, S.H.; Choi, K.S.; et al. The Korean version of the Connor-Davidson Resilience Scale: An extended validation. Stress Health 2012, 28, 319-326. [CrossRef] [PubMed]

44. Coon, C.D.; Cappelleri, J.C. Interpreting Change in Scores on Patient-Reported Outcome Instruments. Ther. Innov. Regul. Sci. 2015, 50, 22-29. [CrossRef] [PubMed]

45. Edlund, M.J.; Martin, B.C.; Fan, M.Y.; Devries, A.; Braden, J.B.; Sullivan, M.D. Risks for opioid abuse and dependence among recipients of chronic opioid therapy: Results from the TROUP study. Drug Alcohol Depend. 2010, 112, 90-98. [CrossRef] [PubMed]

46. Substance Abuse and Mental Health Services Administration. Results from the 2013 National Survey on Drug Use and Health: Summary of National Findings; Substance Abuse and Mental Health Services Administration: Rockville, MD, USA, 2014; HHS Publication No. (SMA) 14-4863. Available online: https:/ / www.samhsa. gov/data/sites/default/files/NSDUHresultsPDFWHTML2013/Web/NSDUHresults2013.pdf (accessed on 27 March 2018).

47. Schnohr, C.; Hojbjerre, L.; Riegels, M.; Ledet, L.; Larsen, T.; Schultz-Larsen, K.; Petersen, L.; Prescott, E.; Grønbaek, M. Does educational level influence the effects of smoking, alcohol, physical activity, and obesity on mortality? A prospective population study. Scand. J. Public Health 2004, 32, 250-256. [CrossRef] [PubMed] 
48. Grant, J.D.; Scherrer, J.F.; Lynskey, M.T.; Agrawal, A.; Duncan, A.E.; Haber, J.R.; Heath, A.C.; Bucholz, K.K. Associations of alcohol, nicotine, cannabis, and drug use/dependence with educational attainment: Evidence from cotwin-control analyses. Alcohol Clin. Exp. Res. 2012, 36, 1412-1420. [CrossRef] [PubMed]

49. Organisation for Economic Co-operation and Development (OECD). Education at a Glance 2017: OECD Indicators; OECD Publishing: Paris, France, 2017; Available online: https: / read.oecd-ilibrary.org/ education/education-at-a-glance-2017_eag-2017-en\#page8 (accessed on 7 May 2018).

50. Morasco, B.J.; Lovejoy, T.I.; Dobscha, S.K. The Relationship between PTSD and Chronic Pain: Mediating Role of Coping Strategies and Depression. Pain 2013, 154, 609-616. [CrossRef] [PubMed]

51. Hudson, J.I.; Pope, H.G. The concept of affective spectrum disorder: Relationship to fibromyalgia and other syndromes of chronic fatigue and chronic muscle pain. Baillière's Clin. Rheumatol. 1994, 8, 839-856. [CrossRef]

52. Crabtree, D.; Ganty, P. Common functional pain syndromes. BJA Educ. 2016, 16, 334-340. [CrossRef]

53. Cheatle, M.D.; Gallagher, R.M. Chronic pain and comorbid mood and substance use disorders: A biopsychosocial treatment approach. Curr. Psychiatry Rep. 2006, 8, 371-376. [CrossRef] [PubMed]

54. Boscarino, J.A.; Rukstalis, M.; Hoffman, S.N.; Han, J.J.; Erlich, P.M.; Gerhard, G.S.; Stewart, W.F. Risk factors for drug dependence among out-patients on opioid therapy in a large US health-care system. Addiction 2010, 105, 1776-1782. [CrossRef] [PubMed]

55. Vietri, J.; Joshi, A.V.; Barsdorf, A.I.; Mardekian, J. Prescription opioid abuse and tampering in the United States: Results of a self-report survey. Pain Med. 2014, 15, 2064-2074. [CrossRef] [PubMed]

56. Markou, A.; Kosten, T.R.; Koob, G.F. Neurobiological similarities in depression and drug dependence: A self-medication hypothesis. Neuropsychopharmacology 1998, 18, 135-174. [CrossRef]

57. Verdam, M.G.E.; Oort, F.J.; Sprangers, M.A.G. Item bias detection in the Hospital Anxiety and Depression Scale using structural equation modeling: Comparison with other item bias detection methods. Qual. Life Res. 2017, 26, 1439-1450. [CrossRef] [PubMed]

58. Witkiewitz, K.; Vowles, K.E. Alcohol and Opioid Use, Co-Use, and Chronic Pain in the Context of the Opioid Epidemic: A Critical Review. Alcohol Clin. Exp. Res. 2018, 42, 478-488. [CrossRef] [PubMed]

59. Dunn, K.M.; Saunders, K.W.; Rutter, C.M.; Banta-Green, C.J.; Merrill, J.O.; Sullivan, M.D.; Weisner, C.M.; Silverberg, M.J.; Campbell, C.I.; Psaty, B.M.; et al. Opioid prescriptions for chronic pain and overdose: A cohort study. Ann. Intern. Med. 2010, 152, 85-92. [CrossRef] [PubMed]

60. Gomes, T.; Mamdani, M.M.; Dhalla, I.A.; Paterson, J.M.; Juurlink, D.N. Opioid dose and drug-related mortality in patients with nonmalignant pain. Arch. Intern. Med. 2011, 171, 686-691. [CrossRef] [PubMed]

61. Dasgupta, N.; Funk, M.J.; Proescholdbell, S.; Hirsch, A.; Ribisl, K.M.; Marshall, S. Cohort Study of the Impact of High-Dose Opioid Analgesics on Overdose Mortality. Pain Med. 2016, 17, 85-98. [CrossRef] [PubMed]

62. Fine, P.G.; Messina, J.; Xie, F.; Rathmell, J. Long-term safety and tolerability of fentanyl buccal tablet for the treatment of breakthrough pain in opioid-tolerant patients with chronic pain: An 18-month study. J. Pain Symptom Manag. 2010, 40, 747-760. [CrossRef] [PubMed]

63. Portenoy, R.K.; Bennett, D.S.; Rauck, R.; Simon, S.; Taylor, D.; Brennan, M.; Shoemaker, S. Prevalence and characteristics of breakthrough pain in opioid-treated patients with chronic noncancer pain. J. Pain 2006, 7, 583-591. [CrossRef] [PubMed]

64. Smith, H. A Comprehensive Review of Rapid-Onset Opioids for Breakthrough Pain. CNS Drugs 2012, 26, 509-535. [CrossRef] [PubMed]

65. Granata, R.; Bossi, P.; Bertulli, R.; Saita, L. Rapid-onset opioids for the treatment of breakthrough cancer pain: Two cases of drug abuse. Pain Med. 2014, 15, 758-761. [CrossRef] [PubMed]

66. Passik, S.D.; Messina, J.; Golsorkhi, A.; Xie, F. Aberrant Drug-Related Behavior Observed During Clinical Studies Involving Patients Taking Chronic Opioid Therapy for Persistent Pain and Fentanyl Buccal Tablet for Breakthrough Pain. J. Pain Symptom Manag. 2011, 41, 116-125. [CrossRef] [PubMed]

67. Kwon, J.H.; Tanco, K.; Hui, D.; Reddy, A.; Bruera, E. Chemical coping versus pseudoaddiction in patients with cancer pain. Palliat. Support. Care 2014, 12, 413-417. [CrossRef] [PubMed]

68. Turner, J.A.; Shortreed, S.M.; Saunders, K.W.; LeResche, L.; Von Korff, M. Association of levels of opioid use with pain and activity interference among patients initiating chronic opioid therapy: A longitudinal study. Pain 2016, 157, 849-857. [CrossRef] [PubMed]

69. Voon, P.; Buxton, J.A.; Wood, E.; Montaner, J.S.; Kerr, T. Dose-response relationship between functional pain interference and nonmedical analgesic use: Findings from a nationally representative Canadian survey. Can. J. Pain 2018, 2, 103-112. [CrossRef] 
70. Jacobs, M.S. Psychological Factors Influencing Chronic Pain and the Impact of Litigation. Curr. Phys. Med. Rehabil. Rep. 2013, 1, 135-141. [CrossRef]

71. Quartana, P.J.; Campbell, C.M.; Edwards, R.R. Pain catastrophizing: A critical review. Expert Rev. Neurother. 2009, 9, 745-758. [CrossRef] [PubMed]

72. Eccleston, C.; Morley, S.J.; Williams, A.C. Psychological approaches to chronic pain management: Evidence and challenges. Br. J. Anaesth. 2013, 111, 59-63. [CrossRef] [PubMed]

73. McCracken, L.M.; Turk, D.C. Behavioral and Cognitive-Behavioral Treatment for Chronic Pain: Outcome, Predictors of Outcome, and Treatment Process. Spine (Phila Pa 1976) 2002, 27, 2564-2573. [CrossRef]

74. Lee, C.S.; Kim, D.; Park, S.Y.; Lee, C.S.; Kim, Y.C.; Moon, J.Y. Usefulness of the Korean Version of the CAGE-Adapted to Include Drugs Combined with Clinical Predictors to Screen for Opioid-related Aberrant Behavior. Anesth. Analg. 2018. [CrossRef] [PubMed]

75. Seo, M.S.; Shim, J.Y.; Choi, Y.S.; Kim, D.Y.; Hwang, I.G.; Baek, S.K.; Shin, J.Y.; Lee, J.; Lee, C.G. Physician's Attitude toward Treating Breakthrough Cancer Pain in Korea. Korean J. Hosp. Palliat. Care 2017, 20, 18-25. [CrossRef]

76. Levy, B.; Paulozzi, L.; Mack, K.A.; Jones, C.M. Trends in Opioid Analgesic-Prescribing Rates by Specialty, U.S., 2007-2012. Am. J. Prev. Med. 2015, 49, 409-413. [CrossRef] [PubMed]

77. Jamison, R.N.; Sheehan, K.A.; Scanlan, E.; Matthews, M.; Ross, E.L. Beliefs and attitudes about opioid prescribing and chronic pain management: Survey of primary care providers. J. Opioid Manag. 2014, 10, 375-382. [CrossRef] [PubMed]

78. Webster, F.; Bremner, S.; Oosenbrug, E.; Durant, S.; McCartney, C.J.; Katz, J. From Opiophobia to Overprescribing: A Critical Scoping Review of Medical Education Training for Chronic Pain. Pain Med. 2017, 18, 1467-1475. [CrossRef] [PubMed]

79. Cleary, J.; Radbruch, L.; Torode, J.; Cherny, N.I. Formulary availability and regulatory barriers to accessibility of opioids for cancer pain in Asia: A report from the Global Opioid Policy Initiative (GOPI). Ann. Oncol. 2013, 24 (Suppl. 11), xi24-xi32. [CrossRef] [PubMed]

80. Cho, B.I. Drug Control Policy in Korea. Vancouver, British Columbia, Canada: International Centre for Criminal Law Reform and Criminal Justice Policy 2014. Available online: http: / / www.tcm-intl.com/public/data/\%E6\%B3\%95\%E5\%BE\%8B\%E6\%B3\%95\%E8\%A7\%84/\%E5\%9B\%BD\% E9\%99\%85/\%E9\%9F\%A9\%E5\%9B\%BD/Drug\%20Control\%20Policy\%20in\%20Korea.pdf (accessed on 12 May 2018).

81. Feng, L.Y.; Yu, W.J.; Chang, W.T.; Han, E.; Chung, H.; Li, J.H. Comparison of illegal drug use pattern in Taiwan and Korea from 2006 to 2014. Subst. Abuse Treat. Prev. Policy 2016, 11, 34. [CrossRef] [PubMed] 